\title{
Dynamic Nanocellulose Networks for Thermoset-like yet Recyclable Plastics with a high Melt Stiffness and Creep Resistance
}

Anna Peterson, ${ }^{\mathrm{a}}$ Ida Östergren, ${ }^{\mathrm{a}}$ Antiope Lotsari, ${ }^{\mathrm{a}}$ Abhijit Venkatesh, ${ }^{\mathrm{b}}$ Johannes Thunberg, ${ }^{\mathrm{b}}$ Anna Ström, ${ }^{\text {a }}$ Ramiro Rojas, ${ }^{\mathrm{c}}$ Martin Andersson, ${ }^{\mathrm{a}}$ Lars A. Berglund, ${ }^{\mathrm{c}}$ Antal Boldizar, $, \mathrm{d}, \mathrm{d}$ Christian Müller ${ }^{\mathrm{a}, \mathrm{d} *}$

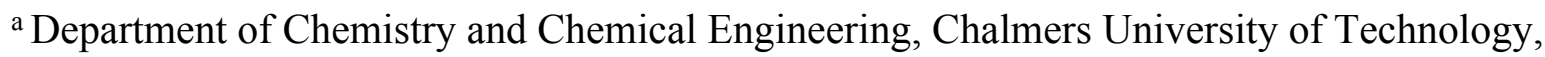
41296 Göteborg, Sweden

${ }^{\mathrm{b}}$ Department of Industrial and Materials Science, Chalmers University of Technology, 412 96 Göteborg, Sweden

${ }^{c}$ Wallenberg Wood Science Center and Department of Fibre and Polymer Technology, KTH Royal Institute of Technology, 11428 Stockholm, Sweden

d Wallenberg Wood Science Center, Chalmers University of Technology, 41296 Göteborg, Sweden

*e-mail: christian.müller@chalmers.se 
a)
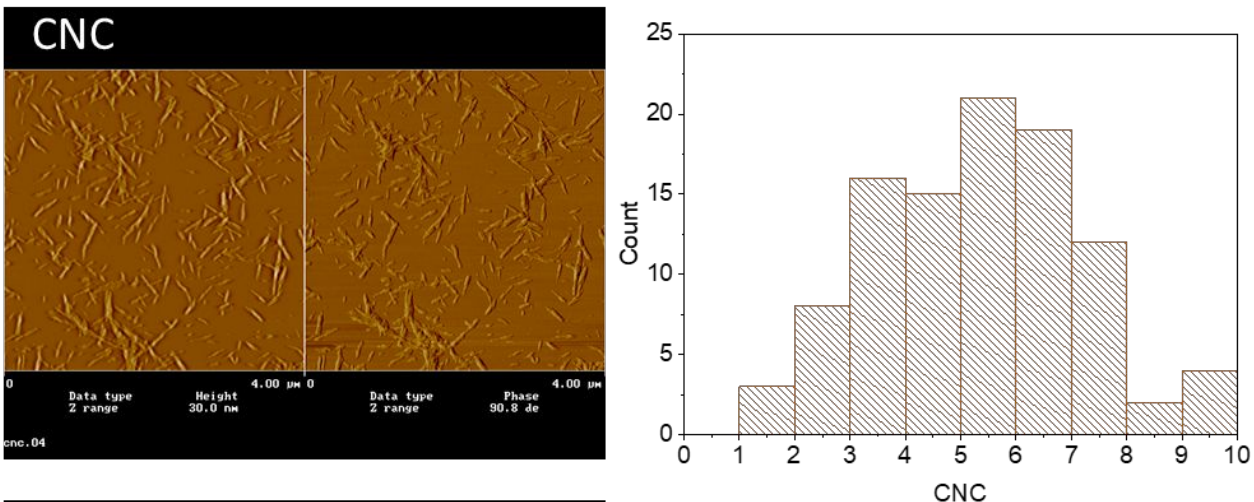

b)
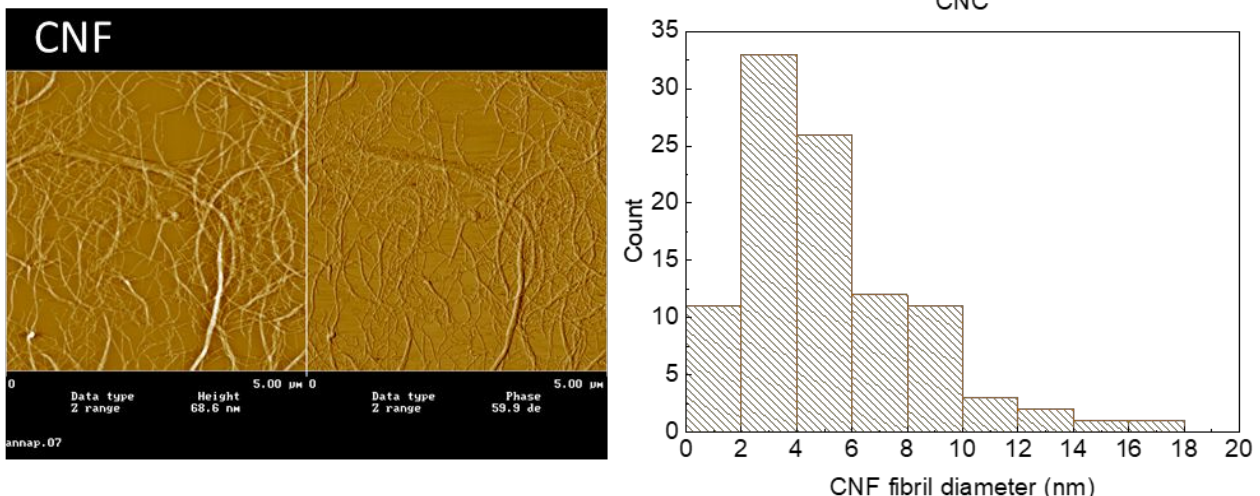

c)
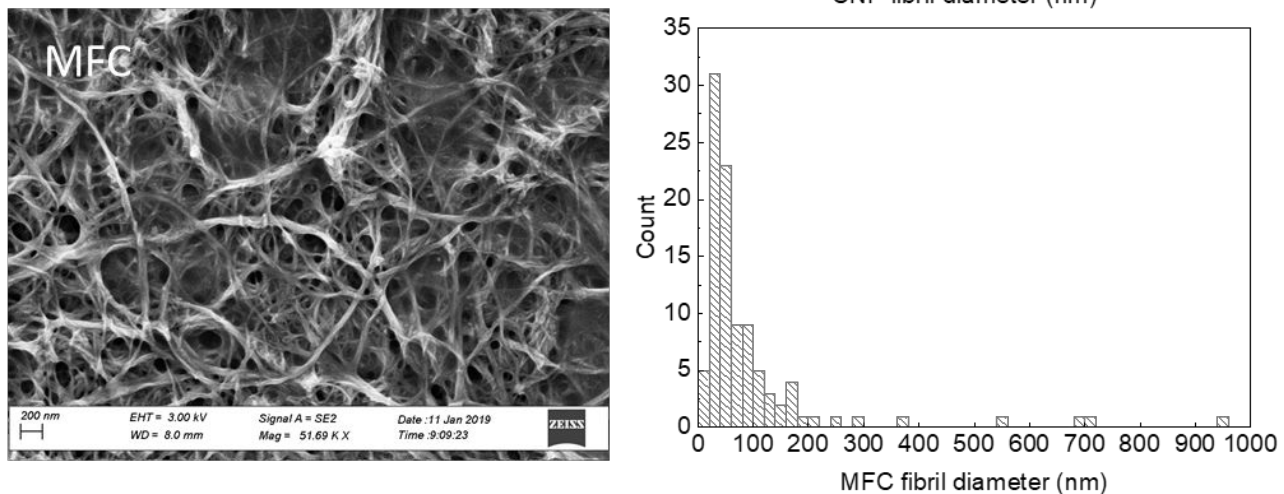

Figure S1. AFM images of (a) CNC and (b) CNF, and (c) SEM image of MFC, as well as corresponding histograms of the measured diameter of the cellulose materials. Measurements of the diameter of $\mathrm{CNC}$, and $\mathrm{CNF}$ were done by measuring the fibril height using the Nanoscope software, $\mathrm{n}=100$. Measurements of the diameter of MFC were done using ImageJ, $\mathrm{n}=100$. The diameter reported in Table 1 was calculated for the fraction of fibrils with a diameter of less than $200 \mathrm{~nm}$; coarser fibrils, which can have a diameter of up to several micrometers were excluded from the analysis. Previously published data ${ }^{1}$ for a similar material indicate that the fraction with a diameter of more than $200 \mathrm{~nm}$ corresponds to about $20 \mathrm{wt} \%$ of the sample. ${ }^{1}$ 


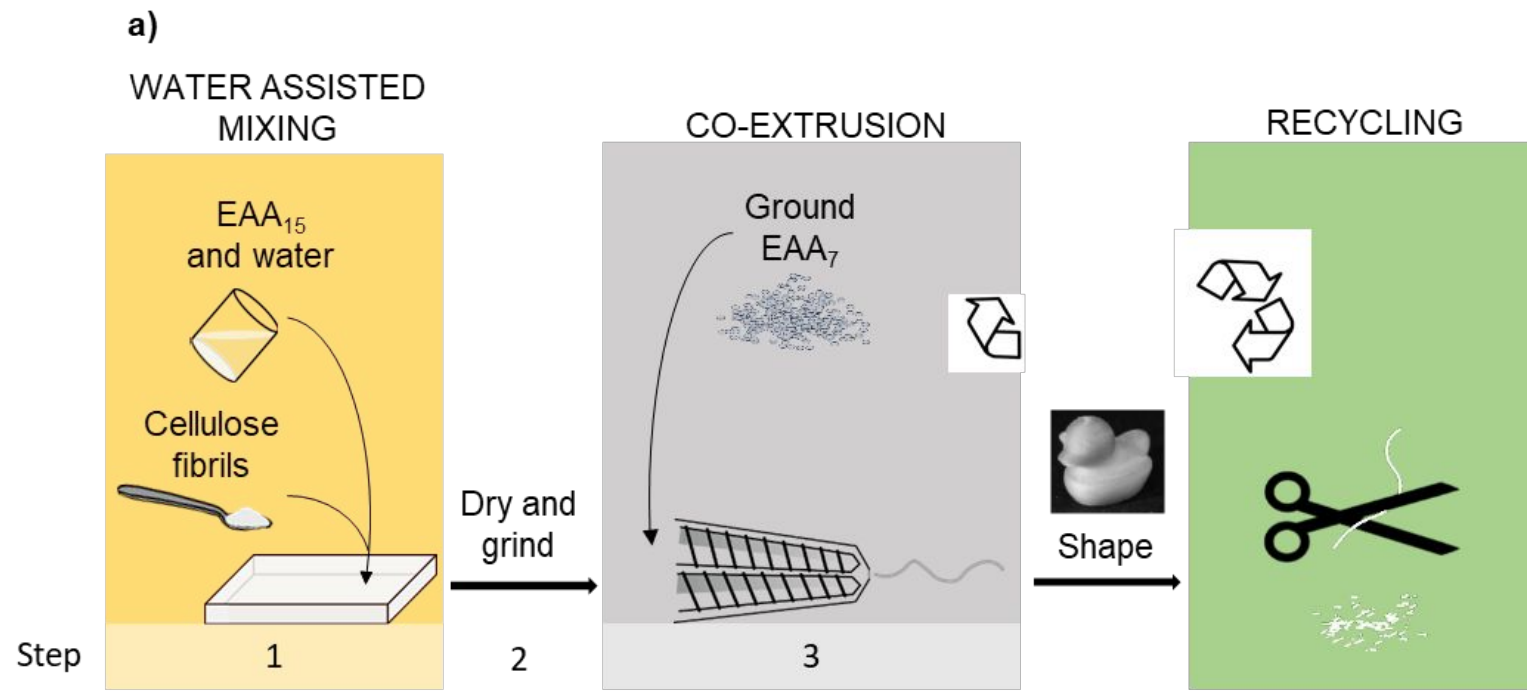

b)

c)
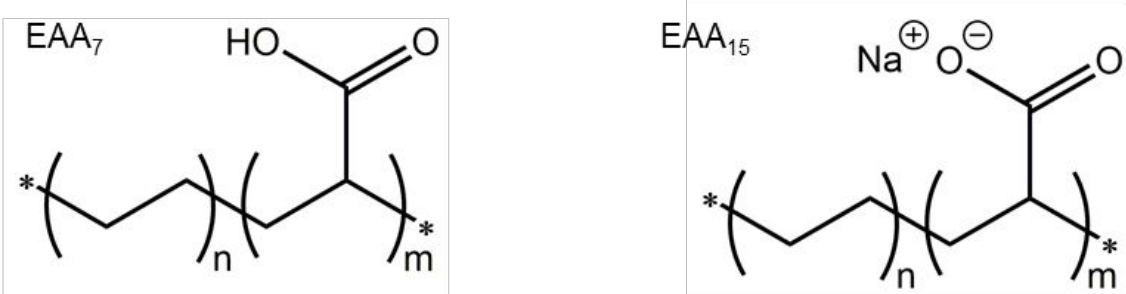

Figure S2. a) Schematic of the manufacturing, processing and recycling of the cellulosic composites. The two part (nanocellulose and $\mathrm{EAA}_{15}$ ) composites only underwent stage 1 , with subsequent drying and melt pressing into sample specimens. The three part (nanocellulose, $\mathrm{EAA}_{15}$ and $\mathrm{EAA}_{7}$ ) composite underwent stages 1-3 and was also demonstrated to be recyclable; b) chemical structure of $\mathrm{EAA}_{7}$, and $\left.\mathbf{c}\right) \mathrm{EAA}_{15}$. 
a)

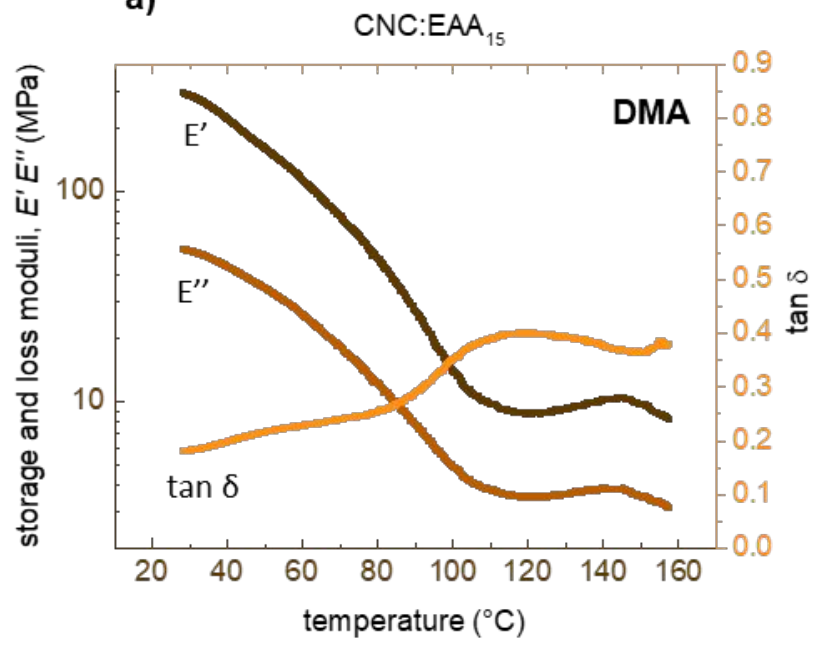

c)

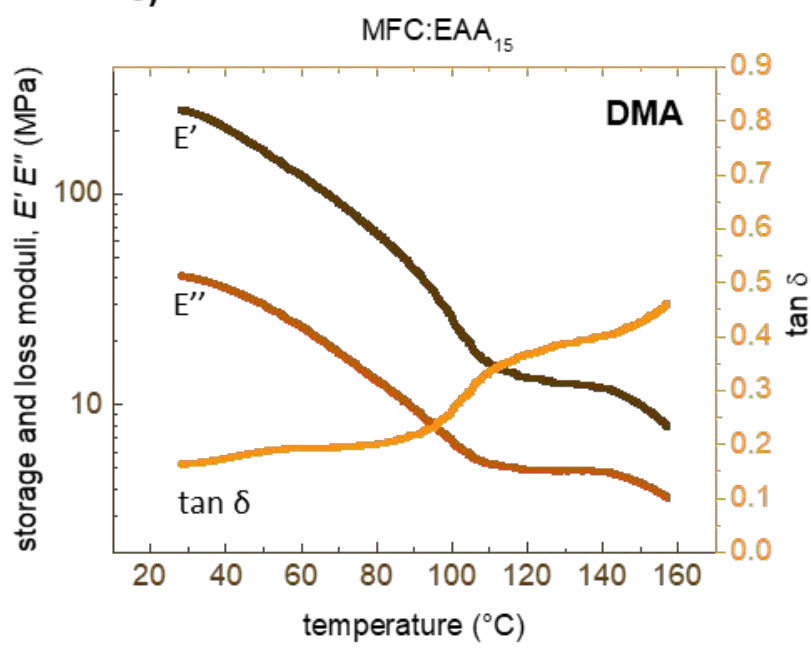

b)

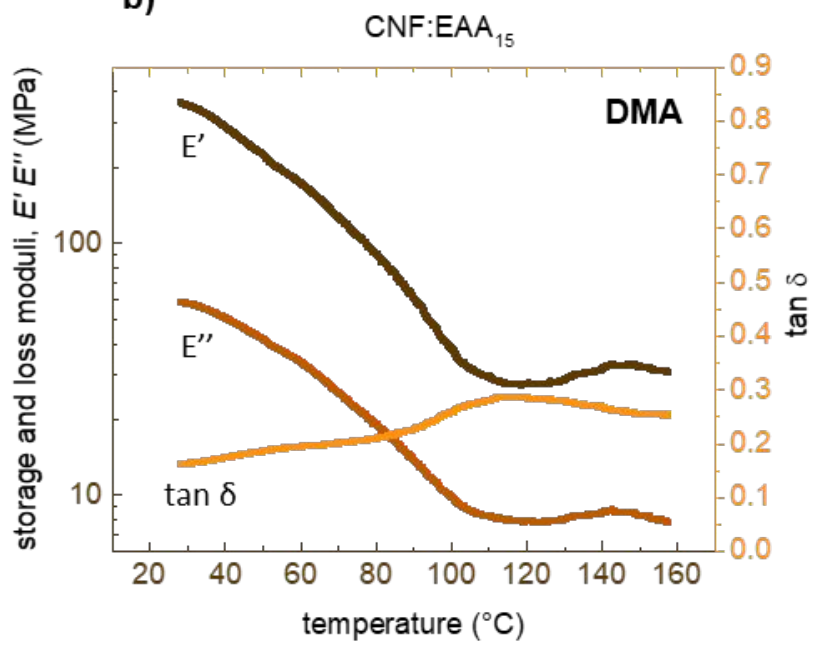

d)

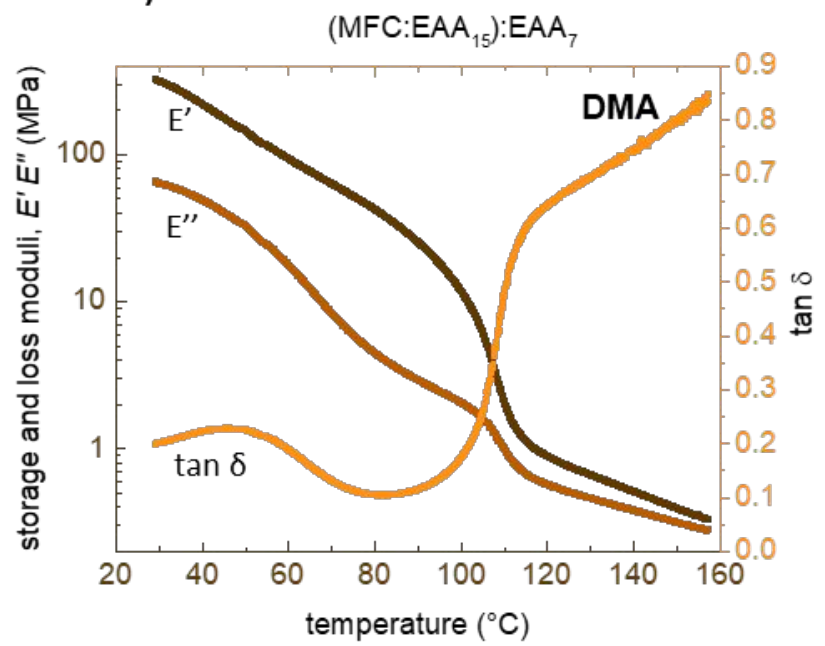

Figure S3. Storage and loss moduli E' and E', respectively, and tan $\delta$ values of composites consisting of a) $\mathrm{CNC}_{\mathrm{EAA}_{15}}$, b) $\left.\left(\mathrm{MFC}_{\mathrm{EAA}}\right)_{15}\right): \mathrm{EAA}_{7}$, c) $\mathrm{MFC}_{\mathrm{EAA}} \mathrm{EA}_{15}$, and d) $\mathrm{CNF}: \mathrm{EAA}_{15}$ (in each case $7.5 \mathrm{wt} \%$ nanocellulose). 


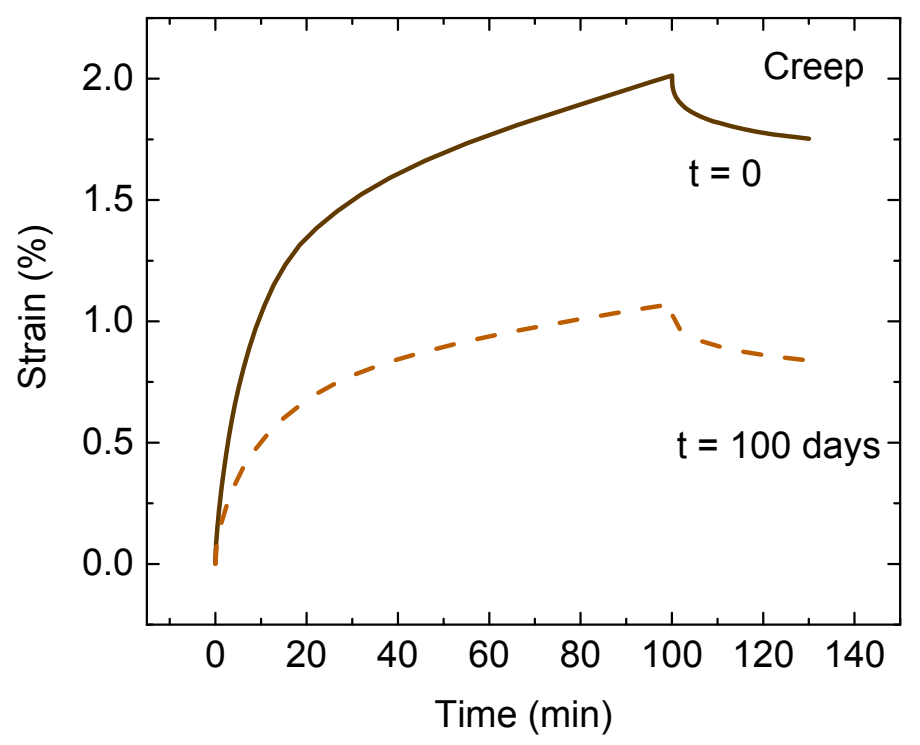

Figure S4. Creep data of two (MFC:EAA ${ }_{15}$ ): $\mathrm{EAA}_{7}$ samples with $14 \mathrm{wt} \% \mathrm{MFC}$, taken from the same batch, measured at time $=0$ and after 100 days storage under atmospheric conditions. 

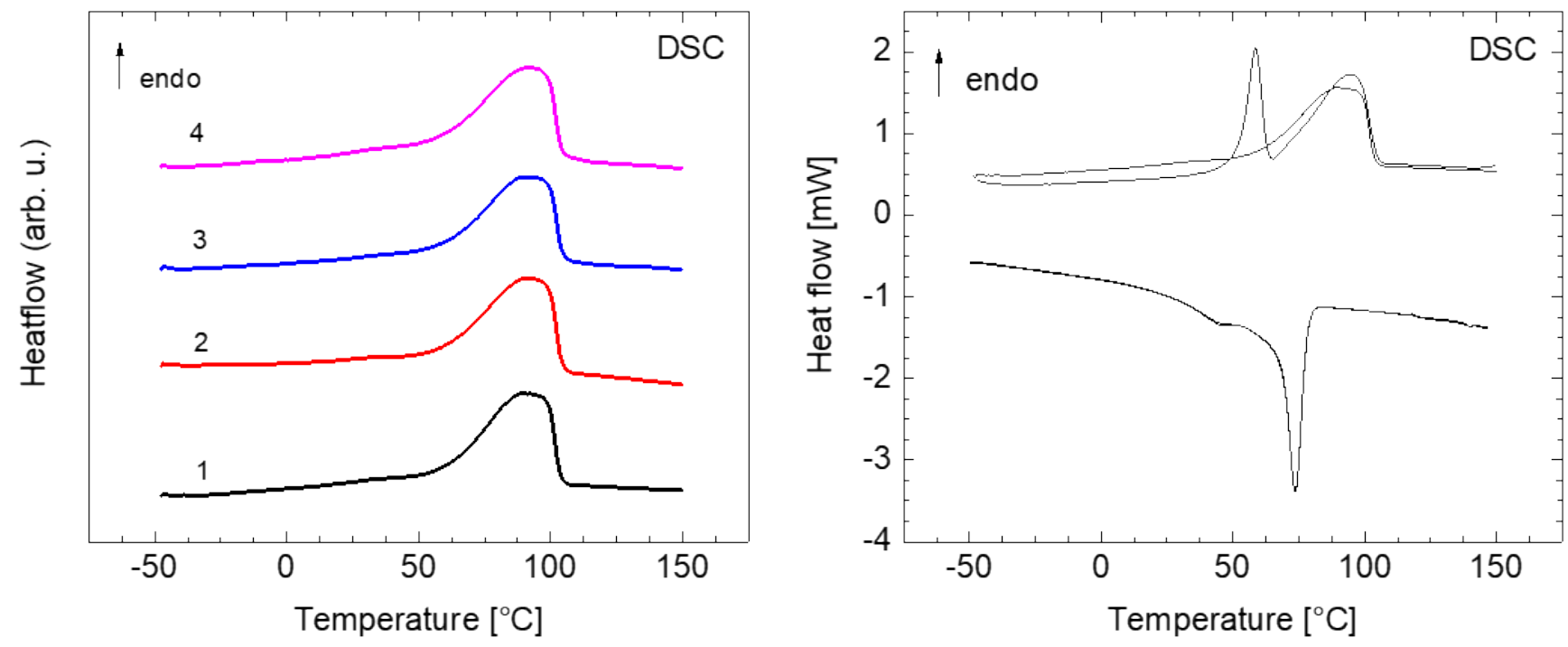

Figure S5. a) DSC second heating thermograms of samples containing $14 \mathrm{wt} \% \mathrm{MFC}$ recycled 1-4 times; b) heating and cooling cycles of the as-extruded sample containing $14 \mathrm{wt} \% \mathrm{MFC}$ before recycling. The sharp meting peak at about $50^{\circ} \mathrm{C}$ is attributed to the melting of secondary crystallites formed upon storage of the EAA copolymer. ${ }^{2}$ 
a)

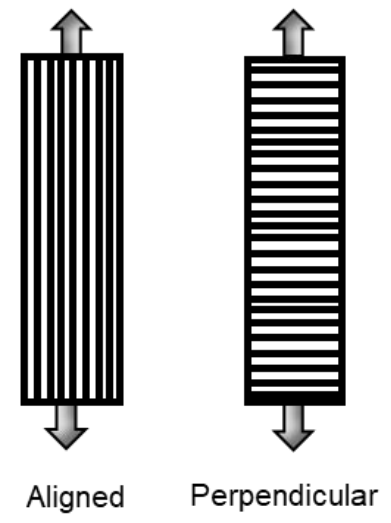

b)

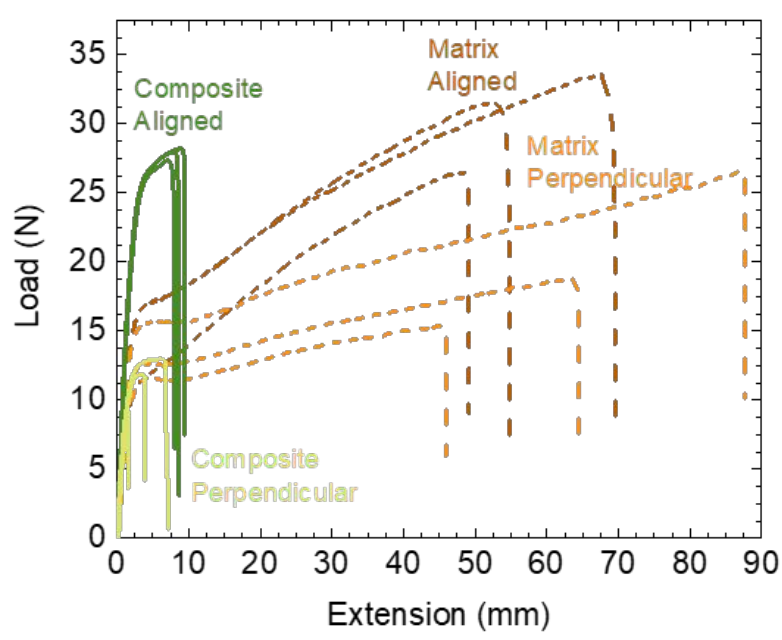

c)

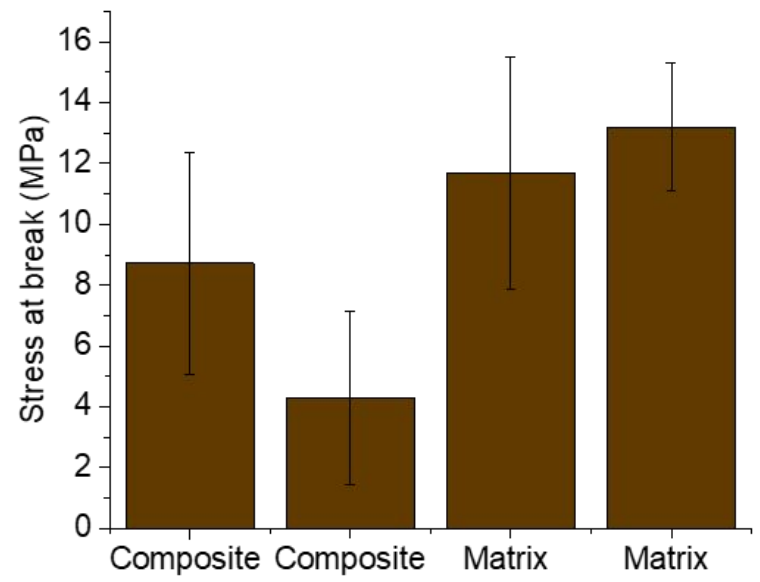

Aligned Perpendicular Aligned Perpendicular
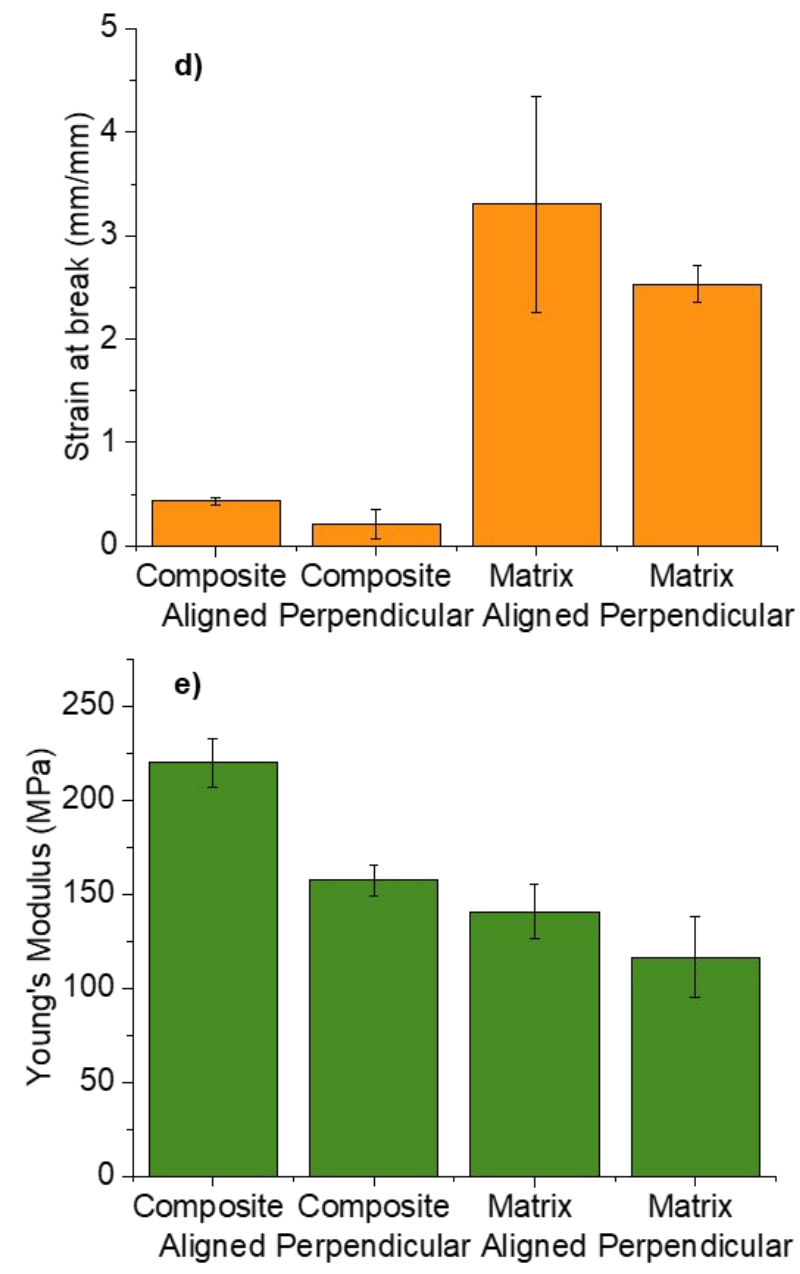

Figure S6. Tensile data of specimens printed by fused filament fabrication (FFF) of a

(MFC:EAA 15 ):EAA 7 composite containing $7.5 \mathrm{wt} \%$ MFC (composite) and a 35:65

$\mathrm{EAA}_{15}: \mathrm{EAA}_{7}$ matrix. a) Orientation of printed strands in relationship to the tensile strain direction; b) tensile data of all samples and the same data as in b) individually represented as c) stress at break, d) strain at break, and e) Young's modulus. 


\section{References}

1. Larsson, P. A.; Riazanova, A. V.; Ciftci, G. C.; Rojas, R.; Ovrebo, H. H.;

Wågberg, L.; Berglund, L. A., Towards optimised size distribution in commercial microfibrillated cellulose: a fractionation approach. Cellulose 2019, $26,1565-1575$.

2. Venkatesh, A.; Thunberg, J.; Moberg, T.; Klingberg, M.; Hammar, L.; Peterson, A.; Müller, C.; Boldizar, A., Cellulose nanofibril-reinforced composites using aqueous dispersed ethylene-acrylic acid copolymer. Cellulose 2018, 25, 45774589. 